\title{
MÍDIAS AUDIOVISUAIS INCLUSIVAS: UMA ABORDAGEM SOBRE A COMUNICAÇÃO ACESSÍVEL A PESSOAS COM DEFICIÊNCIA VISUAL EM CURSOS DE ENSINO À DISTÂNCIA.
}

RIO DE JANEIRO/RJ MAIO/2018

\author{
Daniela Cardoso Tavares - NCE - UFRJ / IPLERIA - daniela.tavares@nce.ufrj.br \\ Filipe Alexandre Santos - IPLERIA (Portugal) - fsantos@ipleiria.pt \\ Carla Freire - IPLERIA (Portugal) - carla.freire@ipleiria.pt \\ Thiago de Melo Ferreira - NCE - UFRJ / HCTE - thiago.ferreira@nce.ufrj.br \\ Marcio Rogério Penha - USP/RP - mrpenha2000@yahoo.com.br \\ José Antonio dos Santos Borges - NCE - UFRJ / HCTE - antonio2@nce.ufrj.br \\ Angélica F.S Dias - NCE - UFRJ / PPGI - angelica@nce.ufrj.br \\ Sandra de Oliveira - Fundação Liberato - sandra.oliveira@liberato.com.br
}

Tipo: Investigação Científica (IC)

Natureza: Descrição de Projeto em Andamento

Categoria: Pesquisa e Avaliação

Setor Educacional: EDUCAÇÃO INFANTIL E FUNDAMENTAL, EDUCAÇÃO MÉDIA E TECNOLÓGICA, EDUCAÇÃO SUPERIOR, EDUCAÇÃO CORPORATIVA, EDUCAÇÃO

CONTINUADA EM GERAL

\begin{abstract}
RESUMO
A pesquisa apresenta um estudo sobre a relevância da adoção da audiodescrição informal na ausência da possibilidade da utilização de uma audiodescrição profissional em conteúdos audiovisuais disponibilizados em cursos na modalidade de Ensino a Distância (EAD). O trabalho apresenta uma avaliação sobre a opinião de voluntários com deficiência visual sobre a eficácia da transmissão da mensagem de um conteúdo audiovisual, que está disponível no Youtube, e faz parte de um curso de ensino em EAD. Os resultados obtidos nesta investigação indicam que a audiodescrição informal pode auxiliar na eficácia da transmissão da mensagem ao público da pesquisa e desta forma podem ser consideradas uma estratégia alternativa eficaz para minimizar as barreiras de comunicação.
\end{abstract}

Palavras-chave: Comunicação Acessível - Deficiência Visual - Educação à Distância - Mídias Audiovisuais

AGRADECIMENTOS

A TODOS OS PARTICIPANTES QUE VOLUNTARIAMENTE PARTICIPARAM DESTA PESQUISA. 


\section{1 - Introdução}

As tecnologias de informação e comunicação (TIC), em particular a Internet e os dispositivos móveis, influenciaram as alterações na estrutura da sociedade (economia, política e cultura). Essas tecnologias contribuem para novas formas de apropriação das mídias, onde se observa uma predominância da imagem e do vídeo nos processos de comunicação. Como exemplo, pode-se destacar o crescimento do uso de vídeos em cursos de ensino à distância, também denominados de EAD (BRAGA, 2015).

Muitas pessoas com diversificados graus de cegueira não conseguem se apropriar dessas mesmas mídias devido às barreiras visuais geradas por elas. Assim, o acesso às informações se precariza. Na tentativa de minimizar essas barreiras nas comunicações, pode-se adotar nos conteúdos audiovisuais o recurso da audiodescrição (TAVARES ET AL., 2016) mas a complexidade da adoção desse recurso nas diversas modalidades de comunicação nos incentiva a buscar alternativas para promover um maior acesso à informação a pessoas com deficiência visual.

O presente trabalho propõe apresentar uma abordagem como forma de encontrar novas alternativas para tomar as medidas presentes em cursos de EaD acessíveis a todos. Por isso, se verifica a necessidade de ampliar os debates na academia sobre Comunicação Acessível Digital. Destacamos que sua relevância está em contribuir com as discussões sobre o acesso de pessoas com deficiência visual aos conteúdos audiovisuais presentes em cursos de Ensino a Distância.

A partir da hipótese de que a audiodescrição informal seja uma estratégia alternativa que contribua com a eficácia da transmissão da mensagem ao espectador com deficiência visual na Internet, este trabalho investiga a adoção da audiodescrição informal (conteúdos audiovisuais com razoável nível de oralidade do palestrante e desprovidos do conhecimento de técnicas específicas para elaboração do vídeo) na ausência da possibilidade da utilização de uma audiodescrição profissional (realizada por audiodescritores) em conteúdos audiovisuais que são disponibilizados em cursos de Ensino a Distância. Vale ressaltar que adoção de um artefato interfere na intenção de utilização ou rejeição por um determinado indivíduo (DIAS, 2007). Podemos inferir que se a utilidade de uso do artefato da audiodescrição for percebida de forma positiva, esta percepção pode influenciar diretamente a intenção de uso. (DIAS, 2013).

\section{1 - Objetivos}

Este trabalho apresenta o estudo sobre a comunicação da pessoa com deficiência 
visual, trabalhos relacionados sobre a importância da audiodescrição e os resultados alcançados na pesquisa. A pesquisa teve como objetivo avaliar a influência do nível de oralidade do narrador do vídeo (audiodescrição informal) no intuito de verificar a sua contribuição para a compreensão da mensagem pelos espectadores com deficiência visual. Então, ainda que não seja o desejado, se entende que a audiodescrição informal pode auxiliar na eficácia da transmissão da mensagem do palestrante para o espectador com deficiência visual.

Com isso, esta pesquisa pretende: A) Verificar se a audiodescrição informal pode ser considerada uma estratégia alternativa para a diminuição de barreiras comunicacionais em mídias audiovisuais presentes em cursos de Ensino a Distância na ausência da audiodescrição profissional; B) Avaliar a influência do nível de oralidade do narrador, para averiguar como este fator contribui para o entendimento da mensagem transmitida ao deficiente visual.

\section{2 - A Comunicação da Pessoa com Deficiência Visual}

Compreende-se que a aquisição de conhecimento é resultado da interação com o ambiente em que os indivíduos se encontram inseridos e da percepção promovida pelo seu sistema sensorial (SOUZA, 2006). Logo, se entende que o processo perceptivo se torna uma importante ferramenta de comunicação, interação e socialização por potencializar a interpretação de sinais interiores e exteriores (RIBEIRO, 2015).

Desta forma, se destaca que as pessoas com deficiência visual utilizam seus sentidos remanescentes (audição, tato, olfato e paladar) como forma de comunicação e interação com o ambiente a sua volta. Para que possam suprir suas necessidades e desejos (se deslocar pela cidade, usar um celular, comprar um produto na Internet, etc) essas pessoas adotam diversas ferramentas denominadas tecnologias assistivas, destinadas a promover a autonomia, qualidade de vida e inclusão social (BRASIL, 2007 p.3), destacando o uso do Braille, do Sistema Dosvox (BORGES, 2009), de leitores de tela para o uso autônomo ao computador para acessar a Internet e os recursos de audiodescrição para conteúdos audiovisuais (GALVÃO, DAMASCENO, LOPES, 2008).

\section{1 - A Importância da Audiodescrição - Mídias Audiovisuais Inclusivas}

O Art. 20 da Lei no 10.098 define como falta de acessibilidade:

II - Barreiras: qualquer entrave ou obstáculo que limite ou impeça o acesso, a liberdade de movimento e a circulação com segurança das pessoas, classificada em: d) barreiras 
nas comunicações: qualquer entrave ou obstáculo que dificulte ou impossibilite a expressão ou o recebimento de mensagens por intermédio dos meios ou sistemas de comunicação, sejam ou não de massa (Brasil, 2000).

A disponibilização de conteúdos audiovisuais na Internet sem acessibilidade às pessoas com deficiência visual podem ser consideradas fortes barreiras na comunicação. $O$ acesso às mensagens transmitidas desta forma são difíceis de serem compreendidas pelas pessoas com deficiência visual. Logo, esses obstáculos impedem a plena interação dessas pessoas com o conteúdo desses materiais e as privam do acesso ao conhecimento (TAVARES ET AL., 2016). Faz-se também importante obedecer aos princípios de Desenho Universal (GAIA, 2008) para que o acesso seja adequado para todos. Em outras palavras, o acesso deve apresentar acessibilidade, sendo a informação perceptível independentemente das suas capacidades ou das condições ambientais e ao baixo esforço físico, e apresentando uma forma eficiente e confortável para o usuário.

Faganello (2013), define que a audiodescrição pode ser definida como um recurso de tecnologia assistiva que objetiva promover uma comunicação acessível a pessoas com deficiência visual, sendo produzida por profissionais treinados (audiodescritores), com a necessidade de um roteiro baseado em técnicas de elaboração específicas. Segundo o autor, este recurso de acessibilidade se torna uma importante estratégia para promover o acesso de pessoas com deficiência visual ao conhecimento e à cultura. Porém, ele também destaca a importância da audiodescrição informal que se caracteriza pela inexistência de técnicas específicas e de um profissional especializado, além de possuir um nível de oralidade razoável do professor ou palestrante. Para ele, este tipo de audiodescrição também pode auxiliar na transferência eficaz da mensagem para o aluno com deficiência visual.

As pessoas com deficiência visual utilizam seus sentidos remanescentes para interação e comunicação, com destaque a audição e no tato. Para realizarem o seu processo perceptivo, a audiodescrição possibilita que a pessoa com deficiência visual construa um raciocínio lógico completo de uma dada mensagem por se basear na percepção auditiva, favorecido pelos conteúdos audiovisuais através do recurso da audiodescrição (FAGANELLO; PENHA, 2013).

A inclusão é um processo que objetiva promover, com equidade e sem distinção, o acesso de todos à sociedade", sendo o conceito de inclusão interligado ao de acessibilidade (SASSAKI, 2009). Segue-se, portanto, que a audiodescrição pode ser promotora de uma comunicação acessível para pessoas com deficiência visual 
(SASSAKI, 2009). A acessibilidade de comunicação permite que as pessoas com deficiência visual construam o seu acervo cognitivo e expressem suas opiniões através da linguagem. Por esta razão, faz-se necessário que as mídias audiovisuais presentes em cursos de Ensino a distância sejam inclusivas. Além disso, a adoção de uma comunicação audiovisual acessível nestes cursos possibilita a ampliação das oportunidades de acesso ao conhecimento às pessoas com deficiência visual (TAVARES ET AL., 2016).

\section{3 - Metodologia}

Esta pesquisa de caráter misto (qualitativo e quantitativo) exploratória (DIAS; SILVA, 2010) foi direcionada das conclusões do estudo conduzido por Tavares Et Al. (2016). Além disso, aborda a temática das Mídias Audiovisuais com o objetivo de encontrar possíveis relações com Comunicação Acessível Digital. Para isso, se pretendeu avaliar a opinião de pessoas com deficiência visual, de forma voluntária, que utilizam vídeos do Youtube para obter conhecimento através da Internet.

Esta pesquisa foi desenvolvida através de um estudo de caso cuja descrição metodológica da coleta de dados e da procura do referencial teórico estão presentes em Tavares et al. (2016). Para a elaboração deste trabalho, se realizou um levantamento bibliográfico e documental sobre os seguintes temas: Audiodescrição, Deficiência Visual e Educação a Distância.

A análise dos resultados foi realizada com base nas respostas dos participantes após assistirem ao vídeo proposto pelos autores. Para a análise qualitativa, observamos as narrativas presentes no discurso das pessoas com deficiência visual durante as entrevistas. A razão para a escolha desta técnica se dá por desejarmos conhecer a opinião dos entrevistados sobre a eficácia da transmissão da mensagem pelo narrador do vídeo para os espectadores com deficiência visual.

Destacamos que a quantificação dos dados desta pesquisa foi possível devido as entrevistas estruturadas serem constituídas de perguntas abertas e fechadas. Assim, a contabilização dos dados se tornou possível. Para isso, adotamos o serviço Google Forms que validou as respostas automaticamente. Porém, se fez necessário digitar o roteiro das entrevistas na plataforma Google Forms. Para a realização deste procedimento, apenas consideramos as perguntas fechadas respondidas pelos participantes com deficiência visual. 
A Razão para optarmos por um estudo misto se relaciona também a necessidade de conhecer o percentual de eficácia da transmissão da mensagem pelo narrador do vídeo aos espectadores de modo a possibilitar uma plena compreensão do conteúdo por este público. Esta informação é bastante importante para avaliarmos o acesso inclusivo dessas pessoas aos materiais audiovisuais que geralmente estão disponíveis no Youtube e são adotados em cursos de ensino a distância.

\section{4 - Resultados e Discussões}

O perfil dos 24 entrevistados com deficiência visual presente nos resultados de Tavares et al. (2016) indicam que $75 \%$ dos participantes alcançaram o nível superior tradicional, ou seja, possuem um razoável nível de conhecimento. Cremos que este indicativo possa ser justificado por dois fatores: um maior acesso das pessoas entrevistadas neste estudo às oportunidades promovidas pelo incentivo às políticas públicas e às tecnologias assistivas. Ainda, segundo esse estudo, 100\% dos participantes utilizam alguma dessas ferramentas para navegar na Internet.

Ainda no que diz respeito ao perfil dos participantes, o trabalho afirma que $91,7 \%$ dos entrevistados assistem a vídeos do YouTube para obter conhecimento. Desta forma, este dado confirma que, apesar de necessitar de algumas adaptações, as pessoas com deficiências visuais desejam se apropriar das mesmas mídias que as demais pessoas da sociedade. Por esta razão, entendemos que estes cidadãos também podem estar inseridos em cursos de ensino superior a distância.

Os autores da pesquisa observaram um percentual diversificado das respostas sobre o nível de perda da informação dado pelos participantes da pesquisa. A tabela abaixo apresenta esses percentuais.

\begin{tabular}{|l|l|}
\hline Perda da informação & Percentual \\
\hline Nenhuma & $20,8 \%$ \\
\hline Até $25 \%$ & $25 \%$ \\
\hline Até 50\% & $29,2 \%$ \\
\hline Mais de 50\% & $25 \%$ \\
\hline $100 \%$ & $0 \%$ \\
\hline
\end{tabular}

Tabela 1- Nível de perda da informação

A Tabela 1, acima apresentada demonstra que o maior percentual $(29,2 \%)$ se encontra no nível de até $50 \%$ de perda da informação. Observamos uma similaridade nos percentuais de até $25 \%$ e mais de $50 \%$, ou seja, em ambos os níveis houve $25 \%$ de prejuízo da explicação do narrador. $20,8 \%$ dos entrevistados relataram obter plenamente 
a mensagem. Enquanto nenhum participante respondeu ocorrer perda total do conteúdo do vídeo.

Apesar da incidência de 29,2\% dos espectadores com deficiência visual colocarem que houve uma perda razoável na transmissão da mensagem pelo palestrante, $70.8 \%$ compreenderam o conteúdo como um todo. Os resultados nos demonstram que a justificativa para isto ocorrer se relaciona ao atendimento do princípio da informação perceptível do desenho universal. Segundo os entrevistados, o motivo da ocorrência do fenômeno é a existência de um razoável percentual $(66,7 \%)$ de oralidade do palestrante e que supriu as expectativas de $58,3 \%$ dos entrevistados.

Desta forma, observamos que o nível de oralidade presente neste vídeo conjuntamente com algumas adaptações efetuadas pelos espectadores com deficiência visual possam ter contribuído para a incidência de $62,5 \%$ de eficácia na transmissão da mensagem aos espectadores com deficiência visual. Assim, se pode dizer que a eficácia da transmissão da mensagem significa promover uma comunicação acessível de modo que o aluno com deficiência visual possa ter uma plena compreensão das tarefas explicadas pelo palestrante.

Destacamos aqui, alguns dados que não foram adotados por TAVARES ET AL (2016) por não fazerem parte do foco da pesquisa, mas que são pertinentes para este trabalho. Então, indicamos nesta pesquisa os seguintes dados: conhecimento dos participantes sobre audiodescrição (91,7\%), assim como o costume dessas pessoas em assistir vídeos com esta tecnologia na Internet (79,2\%). Também consideramos o percentual de eficácia da transmissão da mensagem pelo narrador do vídeo $(62,5 \%)$ e o de pretensão em não desistir de assistir à aula (54,2\%).

Após analisarmos estas estatísticas, compreendemos que o nível de oralidade presente na explicação do palestrante pode ser considerado um fator para um baixo percentual de desistência dos espectadores com deficiência visual em assistir à aula. Além disso, a presença de um nível de oralidade presente nesta mídia audiovisual pode ter contribuído para um nível razoável de eficácia da transmissão do conteúdo desta mídia.

De acordo com o relato do entrevistado A, "A pessoa cega de nascença não tem noção de algo pela descrição sem a utilização do tato". Este depoimento é corroborado pelo relato do participante B. "Porque eu tenho conhecimento das formas geométricas, porém talvez um cego de nascença não tivesse este conhecimento e não conseguisse ter simples e intuitivamente esta informação". 
Também destacamos o depoimento do participante C. Ele acrescenta: "Porque para um cego apenas a explicação do vídeo não é suficiente, sendo necessário conjuntamente a explicação e a prática com o programa. Além disso, há a necessidade da disponibilização de uma informação tátil no que diz respeito às figuras geométricas e desenhos".

Outro dado que consideramos relevante é o percentual sobre a existência de audiodescrição nesta mídia audiovisual. 33,3\% dos entrevistados consideraram que o vídeo possui audiodescrição. Porém, ressaltamos que $91,7 \%$ dos participantes conhecem e 79,2\% colocaram assistir vídeos na Internet com este recurso. Assim, consideramos que nesta mídia audiovisual não ocorre uma audiodescrição profissional, pois a mesma não apresenta as características mencionadas no item 2.1 deste trabalho, mas entendemos a existência de uma audiodescrição informal nesta mídia devido à mesma conter um nível de oralidade razoável do palestrante.

Compreendemos também que um nível de oralidade razoável (audiodescrição informal) também possa ser um auxiliador para o alcance do princípio baixo esforço físico do desenho universal. Ressaltamos que apesar desta estratégia não ser o ideal, proporcionou respectivamente a $20,8 \%$ e $25 \%$ dos entrevistados uma comunicação sem e com poucas barreiras.

\section{5 - Considerações Finais}

Entendemos que a pesquisa alcançou o seu objetivo por encontrar uma importante relação entre Mídias Audiovisuais e Comunicação Acessível Digital. Consideramos que esta relação se dá pelo nível de oralidade presente nesta mídia (audiodescrição informal) ou a adoção da audiodescrição profissional por proporcionar uma diminuição das barreiras causadas pela presença das imagens. Apesar da predominância da percepção visual nos processos comunicacionais, destacamos a importância de mídias como os broadcasts e audiolivros principalmente em regiões do Brasil cujo sinal de Internet é insuficiente.

A adoção de modalidades de mídias apoiadas por outras formas perceptivas (audição, tato, etc) podem contribuir para uma maximização da eficácia da transmissão da mensagem e a sua maior aproximação com os seguintes princípios do desenho universal: informação perceptível e baixo esforço físico. Assim, compreendemos que para se realizar uma comunicação acessível digital se faz necessário atentar para as necessidades e anseios do público alvo que desejamos alcançar. Concluímos que possibilitar uma comunicação acessível digital significa proporcionar o acesso inclusivo 
às mídias a todos sem distinção.

A pesquisa demonstrou que o nível de oralidade presente no vídeo pode ser considerado um dos fatores influenciadores da eficácia da transmissão da mensagem. Porém, a diversidade do tempo em que a pessoa apresenta a deficiência visual e o seu grau de severidade também podem contribuir para uma maior ou menor satisfação do aluno com deficiência visual ao assistir vídeos de cursos de EAD. Por esta razão, entendemos a diversidade das respostas sobre o nível da perda de informação durante a transmissão do vídeo.

Os resultados apresentados neste trabalho demonstram que a audiodescrição informal pode ser considerada uma estratégia alternativa na ausência da audiodescrição profissional por contribuir para a compreensão do conteúdo como um todo. Assim, concluímos que a eficácia da transmissão da mensagem pode influenciar a decisão do aluno em desistir ou não de assistir a aula. Concluímos que a audiodescrição informal contribui para a eficácia da transmissão da mensagem do professor ao aluno com deficiência visual. Porém, os relatos dos participantes mostram a necessidade da adoção de estratégias pedagógicas complementares de modo a diminuir os prejuízos na qualidade do aprendizado de alunos com deficiência visual nessas modalidades de ensino. Desta forma, não basta privilegiar a percepção auditiva mas, adotar estratégias que também utilizem as demais formas perceptivas (tato, olfato, etc).

\section{6 - Referências Bibliográficas}

BORGES, J. A. (2009). Do Braille ao Dosvox- Diferenças nas vidas dos cegos brasileiros [Tese de Doutorado]. Coppe Sistemas, UFRJ, Rio de Janeiro.

BRAGA , D.B. (2015). Tecnologias digitais da informação e comunicação e participação social possibilidades e contradições / Derilse Bértoli Braga, (org.). - São Paulo : Cortez, 2015. Vários autores.

BRASIL (2000). Decreto no 10.098/2000.

BRASIL (2007). Secretaria Especial dos Direitos Humanos. Ata VII Reunião do Comitê de Ajudas Técnicas: CAT CORDE / SEDH / PR - 13 e 14/12/2007.

DIAS, A. F. S Fatores Motivacionais para a Adoção de Tecnologia: Um estudo de caso com Portadores de Deficiência Visual no Rio de Janeiro. Dissertação de Mestrado UFRJ, 2007. 
DIAS, A. F. S., FRANÇA, J. B.; BORGES, M. R. S., SILVA, M. F. Tecnologia Assistiva e Aprendizagem Colaborativa : Um survey com deficientes visual em ambiente virtual de aprendizagem a partir do Modelo TAM, Nuevas Ideas en Informática Educativa - TISE 2013, Porto Alegre - RS.

DIAS Donaldo de Souza; SILVA, Mônica Ferreira da. Como escrever uma monografia: manual de elaboração com exemplos e exercícios. São Paulo: Atlas, 2010.

FAGANELLO, C. (2013) Guia de cinema e vídeo para cegos e surdos. Disponível em: https://goo.gl/MTME6C (Visitado em: 20/04/2018).

GAIA. Princípios do desenho Universal. 2008.

GALVÃO Fo, T.; DAMASCENO, L. L.. Tecnologia assistiva em ambiente computacional: recursos para a autonomia e inclusão socio-digital da pessoa com deficiência. Boletín del Real Patronato Sobre Discapacidad, Madri, n. 63, p. 1423, abr. 2008.

PENHA, M. R. Percepção de comprimento de linha por mediador tátil em deficientes visuais, videntes vendados e videntes: influências do material do mediador e do plano espacial dos estímulos. 2013. Tese (Doutorado) - Faculdade de Filosofia, Ciências e Letras, USP, Ribeirão Preto, 2013.

RIBEIRO, P. A importância da percepção humana. 2015.

SASSAKI, R. (2009). Inclusão: acessibilidade no lazer, trabalho e educação. Revista Nacional de Reabilitação (Reação), São Paulo, (12), p. 10-16.

SOUSA, Jorge Pedro. Elementos de Teoria e Pesquisa da Comunicação e dos Media. 2. ed. rev. amp. Porto, 2006

Desafios enfrentados pelos países em desenvolvimento na educação formal e informal. Novo Hamburgo: FETLSVC, 2015. p.405-506.Vol. 16 No. 1 | Julho de 2016

TAVARES ET AL, 2016. Inclusão cultural de Deficientes visuais: Uma análise da acessibilidade de materiais audiovisuais. Disponível em: http://revistastecnologicocomfenalco.info/index.php/teknos/article/view/811, (Visitado em: 20/04/2018). 